\title{
Der sprechende Held: Darstellungsstrategien des frühneuzeitlichen politischen Gedichts am Beispiel der Auseinandersetzungen um Heinrich den Jüngeren von Braunschweig-Wolfenbüttel und Wilhelm von Oranien
}

\author{
Guillaume van Gemert
}

Einleitung

Die politische Versdichtung, in der die Leitfigur einer Zeitenwende als sprechende Ich-Person auftritt und den eigenen Empfindungen sowie ihren tieferen Seelenregungen Ausdruck verleiht, ihre Beweggründe oder künftige Vorgehensweisen aufdeckt beziehungsweise auf bereits Geschehenes zurückblickt und es gegebenenfalls zu rechtfertigen versucht, scheint bislang weder in der germanistischen Mediävistik noch in der Erforschung der frühneuzeitlichen deutschsprachigen Literatur, genauso wenig aber in der Niederlandistik, insofern sie sich mit den entsprechenden Epochen befasst, als eigenständige Kategorie wahrgenommen worden zu sein. Monographien zur politischen Lyrik des deutschen Mittelalters stufen sie nicht als solche ein, wenn ihnen in der Regel schon deren spezifische Ausprägungen als gesprochene lyrische Großform, biographische Rede, Reimrede, Spruch, Lied oder Klage, durchaus geläufig sind; ${ }^{1}$ die beiden einschlägigen Bände der großen neuen Geschichte der niederländischen Literatur berücksichtigen genauso wenig ihre gattungsspezifische Eigenständigkeit. ${ }^{2}$ Die bislang etwas unzulängliche wissenschaftliche Beschäftigung mit eben dieser spezifischen Ausdifferenzierung dürfte sich nicht zuletzt daraus erklären, dass die Gattungszuordnung der hier näher zu berücksichtigenden Sonderart der politischen Dichtung uneindeutig ist und Klassifizierungen wie Rede und Spruch an und für sich diffuse Momente in sich bergen beziehungsweise zu grobmaschig sind.

Eine nähere Beschäftigung mit der politischen Versdichtung, die den sprechenden Helden in den Mittelpunkt rückt, als einer Kategorie mit spezi-

1 Vgl. etwa Müller (1974).

2 Pleij (2007); Porteman/ Smits-Veldt (2009). 
fischem Eigenwert, ist gerade für die Frühe Neuzeit vollauf gerechtfertigt, da eben diese Variante politischer Selbstapostrophierung damals im Zuge der einsetzenden Territorialisierung einen ausgesprochenen Beitrag zur Identitätsstiftung zu leisten vermochte, und zwar in dem doppelten Sinne, wie Identitätsfindung eben abläuft: durch Konstruktion von Gemeinschaft oder Aufoktroyierung von Gemeinsamkeit zum einen oder durch Abgrenzung gegen das als negativ empfundene Fremde zum andern, im Wechselspiel von Eigenheit und Alterität, in der komplizierten Dynamik von Auto- und Heterostereotypie. Der Held, der sich selbst als politische Führungspersönlichkeit profiliert beziehungsweise sich als ablehnenswerte Schreckensgestalt selber desavouiert, ist hier der zentrale Kristallisationspunkt, zum Positiven beziehungsweise zum Negativen hin, aber immer im Dienste einer sich verwirklichenden neuen kollektiven Identität.

Die hier näher zu berücksichtigende Dichtart bewährt sich besonders in Umbruchszeiten, wie den Zeitläuften der sich durchsetzenden Reformation in den deutschen Landen zum einen, und des Ringens um staatliche Eigenheit im Prozess der niederländischen Loslösung aus der spanischen Herrschaft, dem auch ein ausgesprochen konfessionelles Moment innewohnte, zum andern. Eine Analyse der Strukturen der politischen Dichtung, die sich des sprechenden Helden bedient, in der Art und Weise, wie sie sich im deutschen Sprachraum im 16. Jahrhundert und in den Niederlanden zur Zeit der Abnabelung von Spanien artikulierte, und eine Aufdeckung der in eben diesem Kontext gehandhabten Strategien lassen die unterschwelligen Mechanismen durchscheinen, die bei Territorialisierung und Nationwerdung zum Tragen kommen. Insgesamt lässt sich auch hier eine zweifache Zielrichtung beobachten: Die dichterische Darstellung des sprechenden Helden kann paränetisch-apologetisch angelegt sein und den Helden zum vorbildlichen Freiheitskämpfer hochstilisieren beziehungsweise auf ironische Entlarvung der Selbstgefälligkeit der missliebigen Herrscherpersönlichkeit setzen und diese als Mitte einer verkehrten Welt der Lächerlichkeit preisgeben.

Beide Zielrichtungen der politischen Versdichtung um den sprechenden Helden sollen hier jeweils an einem konkreten Kasus exemplifiziert werden: zunächst die negative Stoßrichtung an Herzog Heinrich dem Jüngeren von Braunschweig $^{3}$ (1489-1568), der ein ausgesprochener Gegner der Reformation war und der, nicht zuletzt wohl auch, weil Luther ihn 1541 in seinem Pamphlet Wider Hans Worst aufs Korn genommen hatte, ${ }^{4}$ gewiss nicht ganz mit Recht, in aller Breite als Galionsfigur der unreflektierten Ablehnung des Neuen,

3 Zu Heinrich dem Jüngeren vgl. ADB. Bd. 11: 495-500; NDB. Bd. 8: 351-352; Koldewey (1883).

4 Luther: Wider Hans Worst 1541. Edition: Luther (1914) 461-572. 
angeblich Besseren in religiosis sowie als Inbegriff des grobschlächtigen Haudegens und verlogenen Sinnlichkeitsapostels ausgemalt wird. Als sein positives Pendant soll hier Wilhelm von Oranien ${ }^{5}\left(1_{33}-1584\right)$, der auf der Dillenburg geborene Nassauergraf, firmieren, der als angeblich integerer und moralisch vorbildlicher Held die Niederlande aus selbstloser Vaterlandsliebe und mit uneigennützigem Einsatz für die reformierte Konfession in die Unabhängigkeit geführt haben soll. Beide, Heinrich der Jüngere von Braunschweig sowie Wilhelm von Oranien, sind so zu Demonstrationsfiguren politischer Intentionen geworden, in negativer beziehungsweise in positiver Spiegelfunktion.

Wilhelm von Oraniens dichterische Vereinnahmung als sprechende politische Leitfigur mit positivem Vorbildwert soll im Folgenden exemplifiziert werden am bekannten Lied Wilhelmus van Nassouwe, das wohl zwischen 1568 und 1572 entstand und seit 1932 als niederländische Nationalhymne gilt. ${ }^{6}$ Zwei Aktualisierungen aus dem ersten Viertel des 17. Jahrhunderts, die sich um die Söhne, Moritz ${ }^{7}$ (1567-1625) und Friedrich Heinrich ${ }^{8}$ (1584-1647), zugleich die unmittelbaren Nachfolger des Landesvaters der niederländischen Republik, ranken, sollen es als weitgehend gleich angelegtes Kontrastgut kontextualisieren: erstere, anonym erschienen, wie die Vorlage auch, stammt aus der Zeit um 16oo, ${ }^{9}$ letztere, die wohl als Begrüßungsgedicht zur Übernahme der Statthalterschaft durch Friedrich Heinrich gedacht war, das Princelied von $1625,{ }^{10}$ wurde verfasst von Joost van den Vondel ${ }^{11}\left(15^{8} 7^{-1679}\right)$, dem wohl angesehensten Dichter des niederländischen 17. Jahrhunderts, der als Konvertit ein ausgewiesener Gegner von Moritz' nicht gerade toleranter Religionspolitik war und daher große Hoffnung auf Friedrich Heinrich setzte. Die literarische Diffamierung Heinrichs des Jüngeren zur antiprotestantischen Abschreckungsgestalt fast teuflischen Ausmaßes, ja zum gottlosen Tyrannen, der sich selbst entlarvt, wird dargetan an zwei polemischen Streitgedichten. Das erste, Hertzog Heinrichs von Braunschweigs klage Liedt, stammt vom bekannten Verfechter der Reformation Burkhard Waldis ${ }^{2}$ (um 1490/95-1556); es ist in das Jahr $1542 \mathrm{zu}$

5 Zu Wilhelm von Oranien vgl. NNBW. Bd. 1, Sp. 1539-1547; Deursen (1995); Mörke (2007).

6 Vgl. dazu Bruin (1998) 16-42, namentlich 18; Grijp (1998) 44-73, namentlich 68.

7 NNBW. Bd. 1, Sp. 1315-1318; Deursen (2000); Zandvliet (2000).

8 NNBW. Bd. 1, Sp. 898-902; Poelhekke (1978).

9 Mauricius van Nassouwen ben ick van Duytschen bloet. o. O. o.J. [um 16oo]. Exemplar: Leiden, Universitätsbibliothek, Sign. Thys. pfl. 1151 .

10 Vondel (1928) 505-506.

11 NNBW. Bd. 4, Sp. 1397-1409; Baumgartner (1882).

12 Zu Waldis vgl. ADв Bd. 40, 701-709; Goedeke (1852); Mittler (1855); Buchenau (1858) 1-40; Könneker (1975) 157-165. 
datieren, ${ }^{13}$ als Heinrich vom Schmalkaldischen Bund, unter der Führung des Kurfürsten von Sachsen sowie des Landgrafen von Hessen, besiegt wurde und der Dichter in hessischen Diensten stand. Es präsentiert sich als Klagelied und muss recht beliebt gewesen, da es insgesamt in vier Ausgaben überliefert ist ${ }^{14}$ und zudem in einer anonymen Bearbeitung, die sich als Spruch versteht. ${ }^{15}$ Ein zweites Streitgedicht, das Heinrich ebenfalls sprechend einführt, dessen Verfasser aber nicht ermittelt werden konnte, Bekentnis und Clag Herzog Heinrichs von Braunschweig des Iüngern, dürfte zur selben Zeit oder etwas später abgefasst worden sein und gibt sich ausdrücklich als Klage beziehungsweise als eine Art Beichte. ${ }^{16}$

Gerade solche politischen Dichtungen um den sprechenden Helden, namentlich die um Heinrich den Jüngeren, lassen die Kontinuität des Formenvorrats vom Mittelalter her sichtbar werden, wenn auch neuzeitliche Ausprägungen wie der Meistergesang oder die Kunst der Rederijker in den Niederlanden diesen scheinbar überlagern. Dass aber hinter neuen Bezeichnungen wie Meistergesang alte Spruch- und Reimrededichtung aufscheint, und das Lied vom Mittelalter bis in die Frühe Neuzeit eine ungebrochene Form- und Ausdruckstradition aufweist, sollte nicht übersehen werden. ${ }^{17}$ Sowohl das Lied um Wilhelm von Oranien, das noch seine Nachfolger legitimieren soll, als auch die Streitgedichte, die gegen Heinrich den Jüngeren ins Feld geführt werden, gewinnen erst auf dem Hintergrund der Tradition, in der sie stehen, der der epischen Lieddichtung beziehungsweise der der Reimrede, ihren vollen Aussagewert.

13 Vgl. Burkhard Waldis: Hertzog Heinrichs von Braunschweigs klage Liedt. In Waldis (1883) 8-14.

14 Vgl. Waldis (1883) X-XI.

15 Burkhard Waldis / Anonymer Bearbeiter: Ein spruch von ainem hungeringen wolffen. In Waldis (1883) 41-46. Die Umdichtung von Waldis' Klagelied Heinrichs dürfte um 156o entstanden sein, vgl. Waldis (1883) 39-40.

16 Bekentnis und Clag $\left({ }^{2} 1863\right) 68-76$. Eine Ausgabe mit dem Titel Bekentnus vnd clag hertzog Heinrichen von Braunschweigs des Jüngern aller seiner hendel/ vnd wie er seine sachen hinfort anzustellen gedencket (o. O. o.J.) besitzt die Herzog August Bibliothek Wolfenbüttel (Sign. Gn Sammelbd. 10 (6)). Es ist nicht auszuschließen, dass Schades Edition eine überarbeitete und modernisierte Fassung beziehungsweise eine ungenaue Abschrift derselben Ausgabe wie die in Wolfenbüttel ist. Trotzdem wird hier nach Schades Edition zitiert, weil sie leichter zugänglich ist als das Originalwerk und die Verszeilen hier durchnummeriert sind, was das Verweisen erleichtert. Mittlerweile ist die Originalausgabe, die auch in Wolfenbüttel vorhanden ist, abrufbar über das Verzeichnis Deutscher Drucke des 16. Jahrhunderts (VD16) auf der Digitalisierungsplattform der Bayerischen Staatsbibliothek. 
2
Die Selbstentlarvungen Heinrichs des Jüngeren von Braunschweig- Wolfenbüttel in der protestantischen polemischen Versdichtung um 1540 durch Burkhard Waldis und den anonymen Verfasser des „Bekentnis“

Heinrich der Jüngere von Braunschweig-Wolfenbüttel war um $1540 \mathrm{zu}$ einem der wohl prominentesten Reformationsgegner unter den norddeutschen Fürsten herangewachsen beziehungsweise hochstilisiert worden. Das verdankte er mehreren Umständen. Zum einen machte er sich durch sein politisches Handeln bei den Befürwortern der Reformation unbeliebt, etwa durch seine Treue zu Kaiser Karl v., für den er 1528 gar mit einer Heeresmacht nach Italien zog mag eine solche Treue auch eher durch realpolitisch-dynastische Erwägungen bedingt gewesen sein, als dass sie aus reiner selbstloser Loyalität dem Lehensherrn gegenüber hervorgegangen wäre; desgleichen durch seine Kampfbereitschaft und seine aggressive Eroberungssucht, deren Opfer etwa der Bischof von Hildesheim wurde; durch seine heftigen Invektiven gegen Vertreter des Schmalkaldischen Bundes, die einst seine Freunde waren; durch seine Beteiligung an der Hinrichtung Thomas Müntzers oder durch die rücksichtslose Auseinandersetzung mit seinem Bruder Wilhelm, den er zwölf Jahre lang gefangen hielt, um ihm die Anerkennung des Erstgeburtsrechts abzutrotzen. Zum anderen bot er sich zur Negativgestalt aus der Sicht der neuen Lehre gleichsam an, und zwar aufgrund seiner persönlichen Lebensführung, etwa durch seine Unmäßigkeit in Speis und Trank, der er allerdings mit manch anderem fürstlichen Zeitgenossen gemeinsam huldigte, durch sein langjähriges außereheliches Verhältnis mit Eva von Trott, einer Hofdame seiner Gattin, die ihm, dem elffachen Familienvater, zehn Kinder gebar und die er sogar zum Schein sterben und feierlich beerdigen ließ, um sie nachher heimlich während angeblicher Jagdpartien umso häufiger auf einem entlegenen Schloss besuchen zu können, aber auch durch unüberlegte Äußerungen, die ihm entfuhren, indem er beispielsweise die Nachricht vom Tod Georgs von Sachsen dahingehend kommentierte, dass ihm lieber gewesen wäre, wenn er statt dessen erfahren hätte, dass Gott selber im Himmel gestorben wäre. ${ }^{18}$ Drittens konnte er dadurch zur Negativgestalt aus reformatorischer Sicht werden, dass die Anhänger der neuen Lehre ihm manches an Schandtaten andichteten, die er wohl kaum verübt haben dürfte, etwa der eigentliche Betreiber von Mordbrennerbanden gewesen zu sein, die sein eigenes Territorium brandschatzten und zerstörten, 
oder den Vertreter der mit ihm verfeindeten Stadt Goslar, Dr. Konrad Dellingshausen, umgebracht und dessen Leiche unter der Mauer des Schlosses Schöningen verscharrt zu haben. Schließlich und viertens wurde er wohl endgültig zur Zielscheibe reformatorischer Anfeindungen durch Luthers Verteidigungsschrift Wider Hans Worst von 1541, die manch alte Anschuldigung gegen Heinrich aufwärmte, die Aufmerksamkeit geballt und in grobschlächtiger Weise auf ihn fokussierte sowie ihn als „Heintz zu Wolffenbüttel“ der Lächerlichkeit preisgab und als feige Memme beziehungsweise als Eunuchen hinstellte:

Und das ich auch zum ende komme, achte ich fur mich, das Heintze Teufel darumb solche böse, lesterliche, lügen bücher fur genomen hab zu schreiben: Er weis, das er bey aller welt viel schendlichern namen hat, und stincket wie ein Teufels dreck, in Deudschen land geschmissen, wolt er vieleicht gern, das er nicht alleine fur andern so scheusslich stüncke, Sondern auch andere löbliche Fürsten bestenckern, ob man seines stancks damit ein wenig vergessen möcht, oder doch nicht sein stanck allein alle nasen füllen müste, zuvor aus, weil dis jar der Mordbrenner geschrey gar uber jn zeter schreyet. Denn solch zeter geschrey zu uberschreien mit leisen worten, das wils nicht thun, Darumb mus er sich also zu zerren und zu plerren, mit fluchen, lestern, liegen, wüeten und toben, obs helffen wolt. Aber es hilfft nicht, Heintz, du schreiest vergeblich, vnd wenn du Wittern und Donnern kundtest, wie Gott selbs, Dis gros, unschüldig blut, zu Eimbeg und anders wo durch deinen Mordbrand vergossen, schreiet gen Himel so starck, das dichs sampt deinen Gesellen gar bald (ob Gott wil) in abgrund der Hellen schreien sol, wird auch nicht ehr auffhören

Das du aber das maul woltest wisschen, Es seien Bosewichter und Schelcke, die solchs von dir, deinen ehren zu nahe, sagen, Ist in dem wol recht geredt und gebest jnen deinen eigen rechten namen. Denn darumb sind sie geschmeucht mit fewr, das sie solche Bösewichter und Schelcke gewest, die jrem heubt und Ertzmordbrenner gedienet haben, Und der Hencker, der sie gerichtet, hat damit dir furgemalet, was du verdienet hettest, wenn man dir solt dein recht thun. Wolan du musst dencken, Es sey eben so mehr in die Helle gerant, als gedrabet, du hasts doch da hin gesetzt, das du Gottes und menschen feind bleiben wilt. Und wo du Gott ermorden kündtest, so würdestu sein ja so wenig schonen als der menschen, wie dein wort zeuget, da Hertzog George gestorben war: Ey, nu wolt ich lieber, das Gott im Himel gestorben were. Davon jtzt nicht alles, denn es ist zu grewlich zu hören, dasselb aus zu streichen, Du hast dir sonst ewigs gedechtnis gnug gestifft, das man Judas, Herodes, Nero und aller welt Bösewichter gegen dir schier wird heilig sprechen müssen. 
Denn ob wol Nero auch Rom ansteckt, thet ers dennoch offenbar und wogets als ein man, wie es zu letzt gehen wurde, Und die andern Mordbrenner stecken Brieve, zeigen jren namen, warnen jre Feinde, wogen auch, das sie dem Hencker in die hende komen. Aber dieser verzagter Schelm und Feltflüchtige Memme thuts alles meuchlings. Er were besser ein Frawen hut, der nichts thun solt, denn wie ein Eunuchus, das ist ein Frawen hut, stehen in einer Narren kappen mit einem Fliegenwedel und der Frawen hüten und des, davon sie frawen heissen (wie es die groben Deudschen nennen). Ich habs von seinen Kriegsleuten gehört, wie ein verzagter Schelm er sey, Ist auch noch nie keines freidigen mans that von jm erhöret, Sondern was er gethan hat, das hat er heimlich oder meuchlings auffs leugnen gethan, oder gegen die, so uber menget oder uber mannet, Seines gleichen oder einen man lesst er wol zu frieden, Das beweiset er nicht allein mit seinem lesterlichen meuchel Ehebruch, sondern auch mit diesem jemerlichen Meuchelmordbrand, on was der stück noch mehr sind. ${ }^{19}$

Der Reformator verfasste sogar ein Spottgedicht auf Heinrich, vielsagend genug auf der Melodie des sogenannten Judaslieds: ${ }^{20}$

Wolan, sie sind verstockt, verblent, dem zorn Gottes ubergeben, Wir müssen dem zorn raum geben und Gottes Gericht lassen gehen, Wollen auch nicht mehr fur ihre Sünde bitten (Wie uns Sanct Johannes leret), sondern von jnen und wider sie, Gott zu lobe und danck singen das Judas Lied auff Heintzen also gedeut:

Ah du arger Heintze, was hastu gethan,

Das du viel Fromer menschen durchs fewr hast morden lan.

Des wirstu in der Helle leiden grosse pein, Lucibers geselle mustu ewig sein, Kyrieleison.

Ah verlorn Papisten, Was habt jr gethan, Das jr die rechten Christen nicht kundtet leben lan?

Des habt die grossen schande, die ewig bleiben sol,

Sie gehet durch alle Lande, und solt jr werden tol, Kyrieleison

19 Luther (1914) $55^{-5}-55^{2}$.

20 Zum Judas-Lied vgl. Liliencron (1884) 227-228 und LII-LV. Der Text lautet: „O du armer Judas, was hastu getan, | daß du deinen herren also verraten hast! | darum mustu leiden in der helle pein, | Lucifers geselle mustu ewig sein. Kyrieleison“. 
Wenn ich dis Liedlin ein mal vol mache, wil ich dem zu Meintz seine leisen auch finden. ${ }^{21}$

Luther mag Heinrich den Jüngeren als Feigling hingestellt haben, dieser war in militärischer Hinsicht jedoch keineswegs als harmlos einzustufen. Er hatte den Bischof von Hildesheim besiegt, und die Feindschaft zum Schmalkaldischen Bund und zu den Städten Goslar und Braunschweig führte immer wieder zu kriegerischen Auseinandersetzungen, die beiden Seiten zu schaffen machten. 1542 wurde Heinrichs Territorium von dem Kurfürsten von Sachsen und dem Landgrafen von Hessen besetzt und sogar die Festung Wolfenbüttel eingenommen, allerdings in Heinrichs Abwesenheit, denn dieser war selber vergeblich im Süden bei Verbündeten auf der Suche nach Unterstützung; da er damals auch in der Abtei Sankt Emmeram in Regensburg Aufnahme fand, wird er gar als Mönch verspottet. ${ }^{22}$ Der gescheiterte Versuch, seine Herrschaft zurückzuerobern, ließ ihn 1545 in die Gefangenschaft des Landgrafen von Hessen geraten, aus der ihn Karl v. erst 1547 nach der Schlacht bei Mühlberg befreite, um ihn wieder in seine alten Rechte einzusetzen. Hier räumte er mit der Schreckensherrschaft der Schmalkaldischen Statthalter auf und versuchte, der sich Bahn brechenden Reformation Einhalt zu gebieten. ${ }^{23}$ Späte Erfolge waren ihm durchaus beschieden: 1553 wusste er in der Schlacht bei Sievershausen im Zuge des sogenannten markgräfischen Krieges Albrecht von Brandenburg-Culmbach zu besiegen, aber er wurde hier selber zur tragischen Gestalt, indem er seine beiden ältesten, katholisch gebliebenen Söhne verlor und auf den jüngsten als Nachfolger angewiesen war, der sich jedoch mittlerweile zur neuen Lehre bekannte. Das mag dazu geführt haben, dass er sich im Alter in den konfessionellen Auseinandersetzungen eher zurückhielt und Toleranz walten ließ.

Heinrichs Niederlagen und seine Siege werden in zahlreichen politischen Versdichtungen, die nicht selten zu historischen Volksliedern geworden sind, thematisiert. ${ }^{24}$ Dabei kehrt manches Detail aus seinem wechselvollen Leben in stereotyper Weise, oft auch als Anspielung, wieder, insofern kommt ein fester Motivbestand zum Einsatz. Solche Lieder sind aber trotz festen Themenvorrats immer Momentaufnahmen, da an einen spezifischen Anlass gebunden. Nur in zwei dieser Lieder, dem klage Liedt und dem Bekentnis, wird Heinrich als

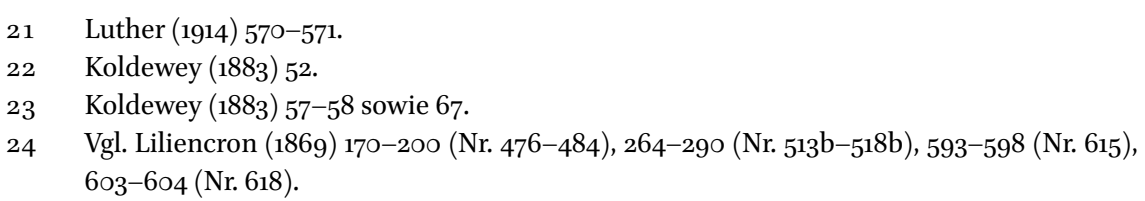


sprechendes Ich aufgeführt. Sie konzentrieren sich in auffälliger Dichte um die Niederlage von 1542 mit Heinrichs vermeintlicher Flucht zu den Verbündeten im Süden. Beide sind im Grunde dürftig kaschiertes Triumphgeschrei aus dem protestantischen Lager, das auf dem Wege der Verteufelung des vertriebenen, aber immerhin noch mächtigen Gegners der Selbstbestätigung beziehungsweise der Verfestigung eigener Positionen dient, um so zum Konstrukt einer neuen kollektiven Identität der siegreichen Partei beizutragen. Beide operieren auch mit weitgehend gleichen stereotypen Versatzstücken aus dem gängigen Materialfundus.

Burkhard Waldis dürfte selber, und zwar im Gefolge seines damaligen Dienstherrn Landgraf Philipp von Hessen, bei der Eroberung Wolfenbüttels zugegen gewesen sein. Er verfasste insgesamt vier Dichtungen zu den Geschehnissen des Jahres 1542 um Heinrich den Jüngeren. ${ }^{25}$ In drei von ihnen tritt die Wolfsmotivik, bedingt durch den Namen von Heinrichs Residenz Wolfenbüttel, mehr oder weniger prominent zutage, im vierten erscheint der Herzog als Wilder Mann. ${ }^{26}$ Das klage Liedt präsentiert den Wolf als treuloses, verräterisches Tier, das auch in den eigenen Reihen Unheil stiftet, feige ist, weil es in Rudeln lebt, somit nicht alleine angreift, und sobald ihm Leid geschieht, kläglich heult. Insgesamt umfasst das klage-Liedt 21 siebenzeilige Strophen, deren Einzelverse jeweils aus jambischen Dreihebern bestehen, bis auf den fünften, der ein Vierheber ist. Das Quartett kennzeichnet sich durch Kreuzreim, in der Terzine als Abgesang findet sich umarmender Reim, wobei Zeile 6, die mittlere der Terzine, reimlos ist. Wort- und Versakzent fallen nicht immer zusammen. Waldis greift hier eine der beliebtesten Liedformen des 16. Jahrhunderts auf; ${ }^{27}$ mit dem Quartett der ersten Strophe spielt er parodistisch auf eine typische Konstellation an: die Klage der Geliebten, die von ihrem Liebhaber scheiden muss, wie sie in dem bekannten Volkslied aus dem Ambraser Liederbuch anklingt:

\footnotetext{
25 Sie sind allesamt abgedruckt in:Waldis (1883). Es handelt sich, neben dem klage-Liedt, um die Warhafftige bescreibung/ der Belegerung vnd Schantzens/ für dem Haus Wolfenbüttel. Durch die Durchleuchten Hochgebornen Fürsten/Churfürsten zu Sachssen/Vnd Landgraff Philipssen zu Hessen. Gescheen den 9. Augusti/ des 42. Jars (Waldis (1883) 2-7), Wie der Lycaon von Wolffenbuttel/ itz newlich in einen Munch vorwandelt ist (Waldis (1883) 15-23) und um Der Wilde Man von Wolffenbuttel (Waldis (1883) 25-38).

26 Vgl. dazu auch Stopp (1970) 200-234.

27 Dazu Frank (1993) 534-536.
} 
Ich stund an einem morgen

heimlich an einem ort;

Da hett ich mich verborgen,

ich hört klägliche wort

Von einem frewlein hübsch und fein,

das stund bey seinem bulen,

es mus gescheiden sein. ${ }^{28}$

Ein sprechendes Ich ist hier somit unverzichtbar, allerdings ist es bei Waldis, wie in der Liebesklage aus dem Ambraser Liederbuch, verschachtelt: Das Ich in der ersten Strophe ist der Beobachter, der zugleich auch Erzähler ist, doch im Verlauf des beobachteten Geschehens beziehungsweise der Erzählung erscheinen dann auch Hauptpersonen der Erzählung, hier das Fräulein und ihr Liebhaber, dort der Wolf, als Ich.

Ich stundt an einem Morgen

Heimlich an einem ort,

Da hett ich mich verborgen,

Ich hort Klegliche wort

Von einem Wolff, der klagt sich sehr,

Wie jm sein Nest verstöret,

Sein Balck zurrissen wer. ${ }^{29}$

In Waldis' Lied hält der Beobachter sich als Erzähler viel stärker zurück als in der Liebesklage, und der Wolf spricht unmittelbar und wortwörtlich, nicht gefiltert durch einen Erzählerkommentar. Das führt dazu, dass, während in der Liebesklage der Erzähler in der letzten Strophe, der siebten, das Fräulein einfach umfallen und bitterlich weinen ließ, Waldis keinen rechten Schluss findet und sich in seiner 21. Strophe beide Ich-Personen mehr oder weniger vermischen:

Dabey lass ichs jtzt bleiben,

Weil ich nicht weiter kan.

Was sie reden vnd schreiben,

Muss ich geschehen lan.

Damit beschlies ich das gedicht:

28 Das Ambraser Liederbuch vom Jahre 1582 (1845) 229-231 (Nr. 176). Hier: 229.

29 Waldis (1883)10. 
Kan ich mich aber rechen,

So lass ichs warlich nicht. ${ }^{30}$

Es dürfte der erzählende Beobachter sein, der hier als Dichter das Gedicht beschließt. Der klagende Wolf aber lässt es für jetzt gut sein und muss sich gefallen lassen, was andere über ihn reden oder schreiben beziehungsweise was ihm als Diktat auferlegt wird. Der Racheschwur am Schluss dürfte ebenfalls vom Wolf stammen. Mit ihm fließt, in der Warnung vor weiteren Schandtaten Heinrichs, zugleich ein didaktisches Moment ein, das sich mutatis mutandis auch in der Liebesklage aus dem Ambraser Liederbuch findet, sei es viel verspielter: Hier will ein „Schlemmer" das Lied gesungen haben, was wohl das ahnungslose Mädchen vor dem Mann als Lustbold auf der Hut sein lassen will, wenn dies auch unverkennbar im Scherz, als Selbstzurücknahme des Erzählers, gesprochen ist:
Da kehrt er sich herumme, und sprach nit mehr zu jhr, Das frewlein das fiel umme, in einen winckel schier, Und weinet das es schier vergieng, das hat ein schlemmer gesungen, wie es eim frewlein gieng. ${ }^{31}$

Der Vergleich von Waldis' Lied mit der Tradition der Liebesklage eröffnet noch eine weitere Perspektive: In deren geistlicher Umdichtung wird aus dem Abschied der Geliebten ein Abschied vom Leben. ${ }^{32}$ Indem Waldis hier anknüpft, scheint er betonen zu wollen, dass Heinrich zunächst einmal erledigt ist, wenn vielleicht auch nicht endgültig, wie in der letzten Strophe durchscheint.

Die eigentliche Klage des Wolfs, die narratio, die von der ersten Strophe als prooemium und von der letzten als conclusio umrahmt wird, ist eine einzige schonungslose Selbstentblößung Heinrichs. In Strophe 2 beklagt er, noch in der Tradition der Liebesklage, seine Verlassenheit, diesmal allerdings von allen Verbündeten, die ihn in der Stunde der Not, die Strophe 7 schildert, im Stich lassen, ein Thema, das in den Strophen 8 bis einschließlich 11 präzisiert wird, mit Bezugnahme auf einzelne vermeintliche Helfer: Sachsen (Strophe 8),

$30 \quad$ Waldis (1883)14.

31 Ambraser Liederbuch vom Jahre 1582 (1845) 230-231.

$32 \quad$ Frank (1993) 535. 
wobei Heinrichs gotteslästerliche Worte zum Tode Georgs zitiert werden, Bremen (Strophe 9), Mainz und womöglich Bayern (Strophen 10 und 11). Strophe 3 konkretisiert Heinrichs Hybris dahin, dass er Sachsen, Hessen, Braunschweig und Goslar habe bezwingen wollen, die hier allesamt mit ihren heraldischen Attributen vertreten sind. Welche Schandtaten er dazu anwandte, List, Verräterei, Mordbrennen und heimtückische Tötung, zeigen die Strophen 4 bis einschließlich 6:

Drumb liss ich mich fast sehen

Mit Ritterlicher that,

Mit schenden vnd mit schmehen,

Mit list vnd falschem Rath,

Mit lügen vnd vorreterey,

Stifft bey mein Bundgenossen

Viel heimlich Meuterey.

Man sagt, ich hab mit Brennen

Vnd Mord viel schaden than,

Mit rauben, vberrennen

Beschedigt mannigen man:

Das klagt beid Goslar vnd Braunschweig,

Zu Pless der Eseltreiber

Zu Eimbeck Heinrich Deick.

Zum Berlyn Simon Fincken

Vber mich gsungen hat.

$\mathrm{Zu}$ Schening liss vorsincken

Wol in den Wall, vorstath,

Doctor Delingshausen gnant,

Der ist jtzt auffgegraben

Vnd warhafftig erkant. ${ }^{33}$

Da alles aber scheitert, muss er die Flucht, das „Hasen Baner“ (Strophe 7), ergreifen und mit kaiserlichem Geleitbrief sich schmählich aus der eigenen Residenzstadt Wolfenbüttel davonschleichen (Strophe 12), auf deren Stärke er zu Unrecht vertraute und in der nun der Feind herrscht (Strophe 18). Es bleiben Heinrich am Ende nur zwei Helfer, der Teufel als Fürst der Hölle (Belial, Strophe

33 Waldis (1883) 10-11. 
12; Pluto, Strophe 14), der ihn zum Kampf ermahnt, und der Papst, als Mitstreiter gegen die lutherische Reformation, dessen Bannflüche aber wirkungslos geworden sind (Strophe 14-16). Indirekte Didaxis sind Heinrichs Worte, dass man sich nicht auf Menschen verlassen sollte (Strophe 17), aber er zieht daraus die falschen Schlüsse, indem er sich nicht Gott zuwendet, sondern seine Klage beendet mit einem pervertierten Bittgebet (Strophe 19-20) an das ganze höllische Personal aller Zeiten von Kain, über sämtliche alttestamentlichen Bösewichter bis hin zu den verbrecherischsten Kaisern der Antike, das darin mündet, dass er sich Judas' Kuss („buss“) erfleht, der wohl den Inbegriff der verräterischen Treulosigkeit darstellte, wenn „buss“ hier nicht gar auf Judas' Buße, d.h. dessen Selbstmord durch Erhängung, verweist:

Cain, du Fürst der Welte,
Dich ruff ich jtzund an,
Phaaro, du starcker Helte,
Auch Saul, du theurer man,
Achitophel, du trewer Rath,
Absolon vnd Semei,
Ewer gleich man jtzt nicht hat.

Nero, Domiciane,

Euch folg ich willig nach;

Caligula, Juliane,

Jr strebt allzeit nach Rach;

Bey euch ich Ewig bleiben muss,

Helfft, das ich müg erlangen

Am end des Judas buss. ${ }^{34}$

Waldis' klage Liedt ist eine anspielungsreiche Erledigung Heinrichs in der ärgsten, für die damalige hexengläubige Zeit aber wohl auch hinterhältigsten, Art, indem es ihn letztendlich zum Teufelsbündler macht. Dagegen nimmt sich die Wolfsmetaphorik eher harmlos aus, auch wenn man, wie Stopp, ${ }^{35}$ annehmen würde, dass hier noch das Moment des Werwolfs mitschwingt, eine Art von Wiedergängertum, die sich höchstens von der angekündigten Rache in der letzten Strophe her rechtfertigen ließe. Die Aussagekraft des Liedes steckt darin, dass Heinrich hier unmittelbar sprechend als Ich-Person aufgeführt wird, aber

34 Waldis (1883) 13-14.

35 Stopp (1970) namentlich 229-232. 
auch in der fast lückenlosen Verwertung sämtlicher gängiger Heinrich-Stereotype in recht kunstvoller Weise und im intertextuellen Dialog mit einer bewährten Liedtradition.

\section{Bekentnis und Clag Herzog Heinrichs}

Im anonym erschienenen Gedicht Bekentnis und Clag Herzog Heinrichs von Braunschweig des Iüngeren kommt die Wolfsmetaphorik, die Waldis' klage Liedt durchzog, kaum noch zum Tragen. Bloß einmal wird der Wolf erwähnt, und zwar in der Verszeile 229, als der Herzog sich, nach der Eroberung seiner Residenz, in tiefster Not befindet und von allen Verbündeten wegen seiner Schandtaten im Stich gelassen wurde; da erklärt er das damit, dass niemand wegen eines Wolfs den Wildbann brechen, das heißt, das Jagdrecht verletzen, würde:

Ich steck in solcher not zu diser frist

Als ie ein mensch gewesen ist.

Het mich nicht vorsehen zu den vorwanten mein

Daß ich also solt vorlaßen sein.

Weil aber meine thaten so offenbar,

So ist keiner der mir beistehen thar.

Dann ich sie darumb nicht vordencken thue,

Wollen sie anders bei dem iren haben rue.

Was darf man auch von mir singen oder sagen,

Meins unfals halben schreyen oder klagen?

An einem wolf man kein wiltban bricht. ${ }^{36}$

Der Wolf als verachtetes Tier, für das niemand etwas übrighat, versinnbildlicht aber treffend die Konstellation, die das Gedicht evoziert. Heinrich erscheint hier als der verstockte Sünder, der unbelehrbare Verbrecher, der stolz ist auf seine Schandtaten, die - in glatter Verkehrung des mittelalterlichen Wertesystems - seine memoria sichern helfen sollen, und der im Grunde bereits dem Höllengott Pluto ausgeliefert ist, den er aber in seiner Verblendung nicht fürchtet:

Was ich aber vor stücklein mehr gedan,

Das ich itzt nicht außsinnen kan:

$36 \quad$ Bekentnis und Clag $\left({ }^{2} 1863\right)$ 74-75 (V. 229-234). 
Dann meine ret und getreuen dahinden bliben,

Die haben es vleißig auffgeschriben.

Den ich aber gerne sehen wolt,

Der es in seiner memoria alles behalden solt.

Darf wol sagen, man wirt keinen finden

Vor einen meister der mich solt überwinden:

Ich wolt wol behalden den plan

Und mich er darüber reufen lan.

Nun weiß ich nicht, wie ich thu der that:

Ich darft wol einer klugen frauen rat.

Es muß ein anders angefangen sein,

Wann es schon kost das leben mein,

Dann daran ist nicht viel vorloren:

Ich bin bereit dem Pluto außerkoren. ${ }^{37}$

Heinrich soll hier als Inbegriff des Bösen abschrecken und dadurch die entgegengesetzte Position, die der schon gerechten und gottesfürchtigen Anhänger der Reformation, verfestigen: Er wird hier somit zur Konstruktion einer kollektiven Identität aus der Abgrenzung heraus instrumentalisiert. Sein Abschreckungspotential wird noch dadurch gesteigert, dass er in Verkennung der gottgegebenen Ordnungshierarchie, die den Fürsten über das kodifizierte Recht hinaushebt und unmittelbar dem Naturrecht als Abspiegelung des göttlichen Rechts unterordnet, die weltliche Gerichtsbarkeit schon fürchtet, während er sich um Gottes Zorn und die ewige Höllenstrafe nicht im geringsten kümmert:

So hab ich doch er und eid weit vorgeßen.

Was nun von solchem wer mein lon,

Darumb darf man nicht fragen don.

Dann wie etliche gelarte leut vorwar,

Zwelf henker, wenn mans sagen thar,

Etlich urteil und sentenz haben geschloßen,

Welchs alle auß meiner büberei entsproßen:

Do kont man mir balt ein urteil fellen

Und mich darauf vor gericht stellen.

Darumb ich das selbig auch nicht wagen thar,

Möcht sonst komen in größere far.

37 Bekentnis und Clag $\left({ }^{2} 1863\right) 74$ (V. 213-228). 
Doch kan ich bei mir nicht ersinnen,

$\mathrm{Da}$ in ganzer welt weren zu erfinden

Solche büberei und große schand

Die ich geübt hab mit meiner hant.

Sol ich mich nu weiter umb dienst bewerben,

So fürcht ich die untreu möcht auff mich erben.

Aber nach dem sprichwort war,

Was schats, wann mans vorsuchen thar?

Meine botschaft hab ich auß gesant

Mich zu wenden in seltsame lant,

$\mathrm{Zu}$ begeben in den gewaltigen haufen

Do die engel mit brenden laufen.

Dann gleicher gestalt geachtet die herrn mein,

Also wirt auch ihr diener sein.

Do wil ich mich erst gebrauchen lan

Nach allem vorteil wie ichs gelernet han,

Ewig und alzeit ein merer im reich,

(Dem Pluto dar niden ich mich vorgleich)

Mich setzen zu seiner rechten hant

Ein gubernator im selben lant.

Ein fürstentumb wil er mir geben ein:

Das sol ich besitzen vor das mein.

Meine sachen wil ich dahin richten

Und al mein thun darauf schlichten

Daß mein reime bleibt war

Welchen ich gefüret manche jar. ${ }^{38}$

Heinrich als gottloser Höllenbraten wird hier weit weniger subtil präsentiert als bei Burkhard Waldis; die Darstellung insgesamt ist weniger vielschichtig. Die lange Reimrede ist auch in formaler Hinsicht viel einfacher gehalten. Sie besteht aus 302 Versen mit Paarreim, zumeist sind es jambische Vierheber mit freier Senkungsfüllung, unter denen sich gelegentlich auch ein Fünfheber findet. Die Anlage ist ebenfalls wenig kompliziert: Heinrich übt Selbstlob durch Auflistung seiner Schandtaten in ironischer Verkehrung und sucht sich damit zu rechtfertigen, gerade in seiner misslichen Lage als vertriebener Fürst ohne Land. Am Schluss steht die Hölle als große Ironie, die ja die ewige Seligkeit in ihr Gegenteil verkehrt, aber die gerechte Belohnung ist für den Gottesveräch-

$3^{8} \quad$ Bekentnis und Clag $\left({ }^{2} 1863\right){ }_{75}^{-76}$ (V. 242-278). 
ter Heinrich. So kommt die ausgleichende Gerechtigkeit am Ende zur Geltung, und wird die rechte Lehre bestätigt.

Von der Motivik her ist anzunehmen, dass der anonyme Verfasser Waldis' klage Liedt gekannt hat. Sehr vieles daraus kehrt hier wieder, sei es auch weit weniger verschlüsselt und mit Verzicht auf den heraldischen Apparat: Neu ist nur die Anspielung auf Heinrichs ehebrecherisches Verhältnis zu Eva von Trott, der toten junkfrau:

All mein büberei und falsche list, Was ich vom anfang biß zum end getriben Und wie es entlich ist vorbliben:

Der selben sein nicht wenig, als man meint.

Dann ich bedacht hab michs gar voreint, Mir solt kein schalkheit groß noch klein Die selbig außzurichen [sic!] zu vil sein. Wie ich auch getriben mein hurerei Mit der toten junkfrau, steht auch darbei, All mein prackticiern und falscher bericht Der keiser könig und dem reich beschicht, Wie ich auch doctor Delinghausen den fromen man Ermordet und in den wall hab graben lan: Das ist man auch ganz gewis.

Umb des wegen ich mein sel vorlies. ${ }^{39}$

Als Beichte und Klage ist Heinrichs Ich-Aussage hier, wie bei Waldis, ebenfalls rücksichtslose Selbstentblößung. Seine Worte sollen aber zugleich, so heißt es in der als prooemium funktionierenden Leseranrede, zum Epitaphium, zur Grabschrift somit, dienen, was deren Endgültigkeit und die Vergeblichkeit jeglicher Hoffnung auf Bekehrung unterstreichen soll:

Es kan sich ein ieder erinnern wol

Daß man einen vogel bei den federn kennen sol.

Was ich nun für ein man geacht,

Das hab ich in dise schrift gemacht,

Und hab es darumb gethan,

Damit man es solt wißen han,

Wie ich gehandelt bei meinem leben,

39 Bekentnis und Clag $\left({ }^{2} 1863\right) 72$ (V. 130-144). 
Was ich gethan und getriben eben.

Dises sol auch mein epitaphium sein

Darauf ich zubring das leben mein. ${ }^{40}$

Heinrich ist dem Tode anheimgegeben und der Hölle geweiht. Das Motto Injuste egi et iniquitatem feci, ${ }^{41}$ das auf Psalm 106,6 (Peccavimus cum patribus nostris, injuste egimus, iniquitatem fecimus) anspielt, konterkariert ironisch Heinrichs wahre Gesinnung. Gegenüber Waldis klage Liedt ist die Höllenmetaphorik hier ungeheuer verdichtet. Als einer, der stolz die eigenen Schandtaten auflistet, ist Heinrich ein Beichtender ohne Reue, ein skrupelloser „Held“, ein Realpolitiker macchiavellistischen Ausmaßes, das heißt aus der christlicher Perspektive ein Antiheld: Er schmäht Gott hier generell, mit eben den Worten, die er zum Tode Georgs von Sachsen gesagt haben soll, als sein Ansinnen sich zerschlägt:
Aber das spil thet sich also wenden
Unvorsehens under unsern henden, Daß ich lieber hett gewolt,
Der got im himel sterben solt
Dann ein einig mensch auf erden
Dardurch es must underlaßen werden. ${ }^{42}$

So wird durch die Montage von tradierten Versatzstücken im Grunde ein verkehrtes Heldenpos konstruiert. Das didaktische Moment tritt hier prononcierter zutage als bei Waldis, und zwar nicht nur im prooemium und in der conclusio. Durch die Ironie ist es aber zugleich auch impliziter, was noch dadurch verstärkt wird, dass hier, anders als bei Waldis, kein erzählender Beobachter erscheint, so dass Heinrich selbst die eigenen Taten kommentieren muss, was ihn als Lehrer fragwürdig werden lässt, weswegen er sich nur in der Ironie recht als solcher bewähren kann:

Auß disem allen hat ein ieder vornomen

Daß ich auß keinem stein gesprungen,

Sondern daß ich ein man von tugent reich

Also daß man nicht findt meins gleich.

Es ist aber nicht gut daß ich mich selbs lob,

$40 \quad$ Bekentnis und Clag $\left({ }^{2} 1863\right) 68$ (Vorrede: „Dem Leser“).

$41 \quad$ Bekentnis und Clag $\left({ }^{2} 1863\right) 68$.

42 Bekentnis und Clag $\left({ }^{2} 1863\right) 70$ (V. $\left.77^{-82}\right)$. 
Sondern habs wol gehort darob.

Wie meine sachen gelegen sein,

Das habt ir alles vornomen fein.

Weil mir aber die nachbarn übel geraten,

So muß ich selbs loben meine thaten.

Aber nach dem gemeinen sprichwort war

Das werk den meister loben thar,

Also vorhoffe ich wol zu bestan

Vor meinen herren vor iederman.

Wil nun besehen wer mich wil fellen,

Weil ich gezogen bin in die hellen

Und da warten der gesellen mein:

Vorhoff, sie sollen auch nicht lang außen sein. ${ }^{43}$

Trotz der Dürftigkeit der dichterischen Gestaltung ist es dem anonymen Verfasser schon gelungen, der eigenen Sache der Reformation mehr Glanz zu verleihen, indem er Heinrich sich selbst als abschreckendes Beispiel hinstellen lässt.

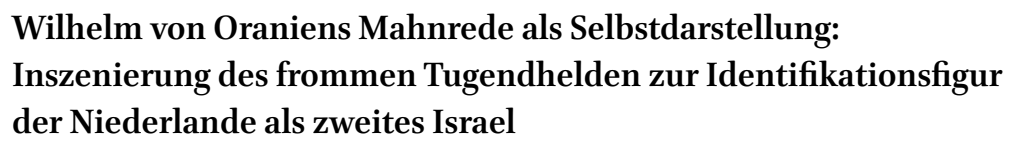

Wilhelm von Oraniens Mahnrede als Selbstdarstellung: Inszenierung des frommen Tugendhelden zur Identifikationsfigur der Niederlande als zweites Israel

Wilhelm von Oranien, der Nassauer-Graf, der durch Vererbung das Fürstentum Orange erhielt, so zum Prinzentitel kam und zum ersten Statthalter der jungen niederländischen Republik wurde, galt, ganz anders als Heinrich der Jüngere von Braunschweig-Wolfenbüttel, keineswegs als Unterdrücker der eigenen Untertanen, sondern vielmehr als Lichtgestalt ohne Makel, als Inbegriff der Frömmigkeit, als Verteidiger der reformierten Konfession gegen spanische Willkür und Zwangsherrschaft, als Freiheitsheld und zugleich als Verfechter der interkonfessionellen Toleranz sowie der Gewissensfreiheit gegen jegliche Unterdrückung. Alles an ihm eignete sich dazu, ihn zur Leitgestalt des aufstrebenden neuen Staatsgefüges zu machen, zur Verkörperung der ersehnten eigenen niederländischen kollektiven Identität im Prozess der Loslösung von Spanien. Dabei wurden seine Schattenseiten, etwa sein Taktieren bis hin zur Unentschlossenheit oder seine langjährige religiöse Indifferenz, glattweg aus-

43 Bekentnis und Clag (2863) 76 (V. 285-302). 
geblendet, erst recht nachdem er 1584 einem von spanischer Seite angezettelten Attentat zum Opfer gefallen war.

Auch seine Flucht ${ }_{15} 67$ vor den heranrückenden Truppen Albas ins Reich auf das Stammschloss Dillenburg wurde ihm weder als Feigheit ausgelegt noch als ein Im-Stich-Lassen der Seinigen in Zeiten der Not, zumal er aus der Ferne die Politik Philipps II. kritisierte und immer wieder mit Söldnertruppen ins Land fiel, um die Spanier zu bekämpfen, wobei mehrere seiner Brüder das Leben verloren und er selber u. a. 1568 bei Maastricht geschlagen wurde. Erst 1572 führten seine Anstrengungen mit französischer und englischer Unterstützung und mit Hilfe der sogenannten Wassergeusen zu einigem Erfolg und konnte er in die Niederlande zurückkehren, wo er eine Art Guerilla-Krieg gegen die Spanier führte, der nach und nach erste Erfolge zeitigte. Seine Versuche, die nördlichen wie die südlichen Provinzen im Kampf gegen die Spanier zu einigen, scheiterten aber an den konfessionellen Unterschieden, zumal er sich selber seit 1573 öffentlich zum Calvinismus bekannte.

Mit der Utrechter Union legte er aber den Grundstein für den Zusammenschluss der sieben nordniederländischen Provinzen, den seine Söhne Moritz und Friedrich Heinrich politisch und militärisch verfestigen sollten; seine diesbezüglichen Initiativen und sein tragischer Tod ließen ihn aber zum Vater des Vaterlands werden. Als solcher und als Freiheitsheld tritt er in vielen Flugblättern und Einblattdrucken der Zeit in Erscheinung.

\section{Das Wilhelmus-Lied}

Als Vater des Vaterlands geriert Wilhelm von Oranien sich im Grunde bereits in dem Wilhelmus-Lied, das wohl ursprünglich als Einblattdruck um 1570 erschien, ${ }^{44}$ das aber in der frühesten Fassung in einer Sammlung patriotischer Kampflieder aus dem Jahre 1577/78, dem sogenannten Geuzenliedboek, überliefert ist. ${ }^{45}$ Im Lied wendet Wilhelm sich aus dem Exil in eigener Person als sprechendes Ich an die Niederländer. Im ursprünglichen Funktionszusammenhang diente es sicher auch zur Rechtfertigung der Flucht Wilhelms im Jahre

44 Zur Datierungsfrage Maljaars (1996) namentlich 151-245. In der Überschrift der Ausgabe von 1570 wird Wilhelm hier bereits als „Pater Patriae“ bezeichnet. Zum Lied insgesamt auch Duyse (1905) 1620-1663 (Nr. 433).

45 Im Folgenden wird es zitiert nach der Fassung im Geuzenliedboek von 1581, die die geläufigere ist, und die abgedruckt ist in: Duyse (1905) 1620-1622. Sie ist ebenfalls enthalten auf einer Loseblattbeilage zu Maljaar (1996). Dort sind auch die an und für sich geringfügigen Varianten zu der Fassung von 1577/78 angegeben. 
1567, der Niederlage bei Maastricht 1568 und seines langjährigen Aufenthalts außerhalb der Niederlande, gerade in einer Zeit, als die Bedrängnis durch die Spanier am intensivsten spürbar war. Der Verfasser ist unbekannt, wenn auch seit Jahren mehrere Namen kursieren; ${ }^{46}$ auf jeden Fall konnte die Verfasserschaft für niemanden endgültig gesichert werden. Die Worte an die Niederländer, die Wilhelm im Lied in den Mund gelegt werden, sind aber ein beredtes Zeugnis rhetorischen Könnens. ${ }^{47}$

Das Lied, das auch in mehreren deutschen Übersetzungen vorliegt, ${ }^{48}$ und das womöglich sogar deutschen Ursprungs gewesen sein könnte, ${ }^{49}$ umfasst insgesamt 15 Strophen, deren Anfangsbuchstaben das Akrostichon "Willem van Nassov" ergeben. Letzteres braucht nicht unbedingt zu implizieren, dass es in der Tradition der sogenannten Rederijker, ${ }^{50}$ der niederländischen Sprachgesellschaften der frühen Neuzeit, mit ihren spezifischen Formtraditionen stünde; in der neueren Forschung wird auch die Nähe zum deutschen Historienlied verstärkt betont, ${ }^{51}$ was den Vergleich mit der politisch-historischen Versdichtung um Heinrich den Jüngeren zusätzlich rechtfertigt.

Das Wilhelmus-Lied ist in achtzeiligen Strophen aus jambischen Dreihebern mit doppeltem Kreuzreim und weiblich / männlich alternierenden Kadenzen abgefasst. Wenn man diese Strophenform auf dem Hintergrund der deutschen Tradition betrachtet, ${ }^{52}$ so eröffnen sich neue Perspektiven: Sie ist nicht nur der am häufigsten anzutreffende Achtzeiler in der deutschen Lieddichtung des 16. und 17. Jahrhunderts, als sogenannter Hildebrandston ist sie ursprünglich in der Heldenepik beheimatet, und eignet sich somit im Verständnis des nationalbewussten 16. Jahrhunderts wohl besonders zur Darbietung, national ' besetzter Stoffe, etwa im Historienlied, insofern es einen Beitrag leistete zur sich herausbildenden Nationalepik. Damit ist auch das Wilhelmus-Lied gewissermaßen für eben diesen Bereich kontextualisiert.

Von der Struktur her springt im Wilhelmus-Lied die offenkundige Zweiteilung ins Auge. ${ }^{53}$ Es schillert zwischen weltlicher Historiendichtung und deren Überhöhung ins Geistliche. Die Strophen 1 bis einschließlich 7 sind noch weit-

\footnotetext{
46 Dazu u. a. Duyse (1905) namentlich 1630-1636. Als Verfasser genannt wurden u. a. Philips van Marnix van Sint Aldegonde, Dirk Volkertsz. Coornhert und J.P. Houwaert.

47 Vgl. Meeuwesse (1964) 8-29.

48 Vgl. dazu Nehlsen (1993). Weiter auch: Duyse (1905), 1622-1625; Harms/ Kemp (1987) 12O121 („Ein Christlich HeldenLiedt“).

49 Vgl. u. a. Maljaars (1996) 204-209.

50 Vgl. u.a. Coigneau (1984) 35-57.

51 Maljaars (1996) 214-215.

52 Vgl. Frank (1993) $573-58$ o.

53 Vgl. Meeuwesse (1951) 393-405; Maljaars (1996) 200-204 und 224-234.
} 
gehend im Irdischen und in der Gegenwart befangen: Hier stellt Wilhelm sich als volksverbundener (van Duytschen bloet), obrigkeitstreuer und gottesfürchtiger Reichsfürst vor, der, obwohl er aus seinem Land vertrieben ist, darauf vertraut, dass Gott ihn wieder in seine verbürgten Rechte einsetzen werde:

\author{
Wilhelmus van Nassouwe \\ ben ick van Duytschen bloet, \\ den vaderlant ghetrouwe \\ blijf ick tot inden doot: \\ een Prince van Oraengien \\ ben ick vrij onverveert, \\ den Coninck van Hispaengien \\ heb ick altijt gheeert.
}

In Godes vrees te leven heb ick altijt betracht, daerom ben ick verdreven, om landt, om luyd ghebracht; maer God sal mij regeren als een goet instrument, dat ick sal wederkeeren in mijnen regiment. ${ }^{54}$

[Wilhelmus von Nassawe/ | bin ich von Teutschem blut/ | dem Vatterland getrewe/ | bleib ich biß in den Todt/ | ein Printze von Vranien/ | bin ich gantz vnuerfehrt/ | den König von Hispanien | hab ich allzeit geehrt. ||

In Gottes forcht zu leben/ | hab ich allzeit betracht/ | darumb bin ich vertrieben/ | vmb Land vnd Leut gebracht/ | aber Gott sol mich regiren/ | als ein gut Instrument/ | daß ich mag wider keren/ | zu meinem Regiment.]

Er ermahnt auch seine Landsleute, die ondersaten aus Strophe 3, zum Gottvertrauen, wobei er den Verlust nächster Angehöriger, den eignen hohen Stand und die eigene Opferbereitschaft beziehungsweise den eigenen Kampfesmut, in den Strophen 4 und 5, als Garanten für künftige Erfolge im Kampf gegen die spanische Tyrannei ansieht:

54 Duyse (1905) 1620. Die deutsche Fassung stammt aus dem Jahre 1579/1580 und ist abgedruckt bei Nehlsen (1993) 353-354, hier 353. 
Lijdt $\mathrm{u}$, mijn ondersaten,

die oprecht zijn van aert, Godt sal $\mathrm{u}$ niet verlaten, al zijt ghy nu beswaert: die vroom begheert te leven, bidt Godt nacht ende dach, dat hy my cracht wil gheven, dat ick u helpen mach.

Lijf en goet al te samen heb ick u niet verschoont, mijn broeders hooch van namen hebbent u oock vertoont; Graef Adolff is ghebleven in Vrieslandt inden slach, sijn siel int eewich leven verwacht den jongsten dach.

Edel en hooch gheboren, van keyserlicken stam, een vorst des rijcks vercoren, als een vroom Christen man, voor Godes woort ghepresen heb ick vrij onversaecht, als een helt sonder vreesen, mijn edel bloet ghewaecht. ${ }^{55}$

[Leit euch mein Vndersassen/ / die auffrecht sein von art/ | Gott wirt euch nit verlassen/ | all seidt jhr nun beschwert/ | wer from begert zu lebe[n]/ | der bitt Gott nacht vnnd tag/ | daß er mir krafft wöll geben/ | daß ich euch helffen mag. \|

Leib vn[d] Gut all zusamen/ | hab ich auch nit gespart/ | mein Brüder hoch von namen/ | haben euch auch verwahrt/ | Graff Adolff ist geblieben/ | in Frießland in der schlacht/ | sein Seel im ewigen leben/ | erwart den jüngsten tag. $\|$

Edel vnd Hochgeboren/ | von Keyserlichem stam[m]/ | ein Fürst des Reichs erkoren/ | als ein fromb Christen Man/ | für Gottes wort 
gepriesen/ | hab ich frey vnuerzagt/ | als ein Held one vresen/ | mein edel blut gewagt.]

Der erste Teil endet mit einem Bittgebet, in den Strophen 6 und 7 , das als Überleitung zum stärker geistlich ausgerichteten zweiten Teil fungiert und in dem Wilhelm als sprechendes Ich sich Gottes Schutz und Hilfe im Kampf gegen die Unterdrücker, beständige Tapferkeit sowie Frömmigkeit erfleht und den Herrn im Himmel bittet, ihn vor den Ränken und der Hinterhältigkeit seiner Verfolger zu behüten:

Mijn schilt ende betrouwen

sijt ghy, o Godt myn Heer,

op u soo wil ick bouwen,

verlaet mij nemmermeer;

dat ick doch vroom mach blijven

$\mathrm{u}$ dienaer taller stondt,

die tyranny verdrijven,

die my mijn hert doorwondt.

Van al die my beswaren, end mijn vervolghers zijn, mijn Godt wilt doch bewaren den trouwen dienaer dijn; dat sy my niet verrasschen in haren boosen moet, haer handen niet en wasschen in mijn onschuldich bloet. ${ }^{56}$

[Mein Schilt vnnd mein vertrawen/ | bistu O Gott mein Herr/ | auff dich so wil ich bawe[n]/ | verlaß mich nimmermehr/ | daß ich doch fromb mög bleiben/ | dir dienen zu aller stund/ | die Tyranney vertreiben/ | die mir mein Hertz durchwundt. ॥

Von allen die mich beschweren/ | vnd mein Verfolger sein/ | mein Gott wöllst doch bewahren/ | den trewen Diener dein/ | daß sie mich nit verraschen/ | in jrem bösen mut/ | jr Hende nit thun waschen/ | in meinem vnschüldigen blut.]

$56 \quad$ Duyse (1905) 1621. Deutsche Fassung: Nehlsen (1993) 353. 
Die Strophen 9 bis 15, die den zweiten Teil ausmachen, wenden sich höheren, metaphysischen Werten zu; in ihnen artikulieren sich Unterordnung unter Gottes Heilsplan, Mitleid mit den unterdrückten Niederländern (Strophe 10), Standhaftigkeit, auch in Widerwärtigkeiten (Strophe 13), und Zuversicht auf einen guten Ausgang des Kampfes (Strophe 9), sogar im Angesicht des Todes, den Gott noch nicht will, da er den Prinzen vor Maastricht erhalten habe (Strophe 11-12):

Na tsuer sal ick ontfanghen van Godt mijn Heer dat soet, daer na so doet verlanghen mijn vorstelick ghemoet; dat is, dat ick mach sterven met eeren in dat velt, een eewich rijck verwerven als een ghetrouwe helt.

Niet doet my meer erbarmen in mijnen wederspoet, dan datmen siet verarmen des Conincks landen goet; dat u de Spaengiaerts crencken, o edel Neerlandt soet, als ick daer aen ghedencke, mijn edel hert dat bloet.

Als een Prins opgheseten met mijner heyres cracht, vanden tyran vermeten heb ick den slach verwacht; die, by Maestricht begraven, bevreesde mijn ghewelt; mijn ruyters sachmen draven seer moedich door dat velt.

Soo het den wille des Heeren op die tijt had gheweest, had ick gheern willen keeren van u dit swaer tempeest; maer de Heer van hier boven, 
die alle dinck regeert, diemen altijt moet loven, en heeftet niet begheert.

Seer prinslick was ghedreven mijn princelick ghemoet; stantvastich is ghebleven mijn hert in teghenspoet; den Heer heb ick ghebeden, van mijnes herten gront, dat hy mijn saeck wil reden, mijn onschult doen bekant. ${ }^{57}$

[Nach sawr werd ich empfange[n]/ | von Gott meim Herren das süß/| darnach so thut verlange[n]/ | mein Fürstelich gemüt/ | daß ich doch möge sterbe[n]/ | mit ehren in de[m] feld/ | ein ewigs Reich erwerben/ / als ein getrewer Held. ||

Nichts thut mich mehr erbarmen/ | in meinem widersput/ | dann daß man sicht verarmen/ | des Königs Landen gut/ | daß euch die Spanier krencken/ | O edel Niderland gut/ | wann ich daran gedencke/ | mein edel Hertz das blut. \|

Als ein Printz auffgesessen/ | mit meiner Heeres Krafft/ | wol vonn dem Feind vermessen/ | hab ich der Schlacht verwacht/ | der bey Mastrich lag begraben/ |beförchtet mein gewalt/ | mein Reuter sah man traben/ sehr mutig durch das feld. ॥

So es der will des Herren | auff die zeit wer gewest/ | hett ich gern wöllen kehren/ | von euch diß schwer tempest/ | aber der Herr dort droben/ | der alle ding regiert/ | den man allzeit muß loben/ | der hat es nit begert. ||

Sehr Christlich war getrieben | mein Fürstelich gemüt/ | standthafftig ist geblieben/ | mein Hertz in widersput/ | den Herr hab ich gebetten/ | auß meines Hertzen grund/| daß er mein Sach wöll richten/ | mein vnschuld machen kundt.]

In Strophe 14 bekundet sich Abschiedsstimmung: Sie enthält den Aufruf Wilhelms an die Niederländer, auf Gott zu vertrauen, auch wenn er, d.h. der Prinz, selber nicht zugegen ist oder womöglich gar bald sterben werde. Zugleich 
dürfte er hier aber den eigenen Tod eschatologisch in eine nahe Endzeiterwartung einbinden, die als endgültige Erlösung, auch der Niederländer aus deren heutigem Leiden, firmiert:
Oorlof, mijn arme schapen, die zijt in grooten noot, $\mathrm{u}$ herder sal niet slapen al zijt ghy nu verstroyt; tot Godt wilt u begheven, sijn heylsaem woort neemt aen, als vrome Christen leven, tsal hier haest zijn ghedaen. ${ }^{58}$

[Vrlaub mein arme Schaffen/ | die seind in grosser not/ | ewr Hirt der sol nit schlaffen/ | vnd seid jr nun verströwt/ | zu Gott wöllt euch begeben/ | sein heilsam wort nempt an/ | als fromme Christen leben/ | sol hie bald sein gethan.]

Mit Beteuerung der eigenen Aufrichtigkeit in Strophe 15 endet das Lied. Sie ist als Pendant zu den Strophen 1 und 2 zu lesen, womit sich das Lied rundet: Am Anfang wie am Schluss bekundet sich die Wertehierarchie, zu der Wilhelm sich als gläubiger Christ und als um das Wohl des ihm anvertrauten Volkes bemühter Statthalter bekennt, aber zugleich auch das Spannungsfeld, in das er sich durch die Geschehnisse der Zeit gedrängt sah, indem er zwar den irdischen (spanischen) König zu ehren, vielmehr aber der höheren göttlichen Majestät zu gehorchen hat um der Gerechtigkeit willen:
Voor Godt wil ick belijden
end zijner grooter macht, dat ick tot gheenen tijden den Coninck heb veracht, dan dat ick Godt den Heere, der hoochster Maiesteyt, heb moeten obedieren inder gherechticheyt. 59 
[Vor Gott wil ich beken[n]en/ | vnd seiner grossen macht/ | daß ich zu keinen zeiten | den König hab veracht/ | dann daß ich Gott dem Herren/ | der höchsten Maiestet/ | hab müssen obediren/ | in der Gerechtigkeit.]

Die zentrale Mitte des Liedes, auch in übertragenem Sinne, bildet Strophe 8: Sie verbindet beide Teile, in ihr kommt aber auch ein für das Verständnis des Liedes entscheidender Gedanke zum Tragen. Die Parallele zum Alten Testament war nicht, wie häufig angenommen wurde, dazu angelegt, Wilhelm ohne weiteres mit David gleichzusetzen. Die biblische Einbindung erfüllt eine Trostfunktion, und zwar vor allem, indem sie an das Selbstverständnis des jungen Staatsgefüges appelliert: Angesprochen wird hier indirekt einer der Gründungsmythen der Republik, namentlich der des zweiten Israel. ${ }^{60}$ Als erste reformierte Nation im europäischen Nordwesten betrachtete die niederländische Republik sich als auserwähltes Volk mit dem missionarischen Auftrag, den rechten Glauben zu verbreiten, wie einst Israel den Monotheismus:
Als David moeste vluchten
voor Saul den tyran,
soo heb ick moeten suchten
met menich edelman;
maer Godt heeft hem verheven,
verlost wt alder noot,
een coninckrijck ghegheven
in Israel, seer groot. ${ }^{61}$

[Als Dauid mußte fliehen/ | für Saulo dem Tyrann/ | so hab ich müssen weichen/| mit manchem Edelman[n]/ | aber Gott thetjhn erheben/ | erlösen auß aller noth/ | ein Königreich jm geben/ | in Israel sehr groß.]

Der biblische Kontext, der hier evoziert wird, ist Bestätigung und Garant des im Entstehen begriffenen niederländischen Selbstbildes zugleich und damit ein entscheidender Beitrag zur Identitätsfindung. Dieser Aufgabe hat sich das ganze Wilhelmus-Lied letztlich verschrieben. Es ist vor allem Rede, ein Monolog des Oranierprinzen, adhortatio und admonitio in einem, ohne unmittelbare Belehrung. Die Debatte, die seit Jahrzehnten in der Forschung geführt wird, ob es sich beim Wilhelmus-Lied um ein Propagandalied, eine Apologie oder

6o Zu den Gründungsmythen der niederländischen Republik vgl. Kloek/ Mijnhardt (2001) 213-242; Lademacher (2007) 114-126.

61 Duyse (1905) 1621. Deutsche Fassung: Nehlsen (1993) 353. 
um ein Trost- und Empfehlungslied handle, ${ }^{62}$ ist unerheblich: Es ist keines von allem in der Reinkultur, und alles zugleich, es ist aber in erster Linie Vehikel zur Identitätskonstruktion; es versprüht Gottvertrauen auf den glücklichen Ausgang des Kampfes gegen Spanien, aber zielt als Beitrag zur Identitätsbildung längerfristig auf den Selbsterhalt des neuen Staates. Die beiden anderen Gedichte in der Wilhelmus-Tradition, die den Söhnen Wilhelms in den Mund gelegt werden, bestätigen die Deutung als Beitrag zur Identitätsfindung, wenn diese hier auch unter anderen Vorzeichen vorangetrieben wird.

\section{Die dichterischen Selbstaussagen von Wilhelms Söhnen Moritz und Friedrich Heinrich in der Tradition des Wilhelmus-Liedes: Fortschreibung der Nationalidee unter anderen Vorzeichen}

Wilhelms Söhne Moritz, Statthalter von 1585-1625, und Friedrich Heinrich, der dasselbe Amt von 1625 bis 1647 innehatte, eigneten sich weniger zur Symbolfigur als ihr Vater. Sie haben sich in erster Linie auf dem Schlachtfeld hervorgetan und waren in militärischer Hinsicht sehr viel erfolgreicher als dieser: Sie verliehen der jungen Republik deren territoriale Integrität und Konsistenz. Das Bewältigen von existentiellen Unwägbarkeiten, im eigenen Leben wie in dem des werdenden Staates, wurde ihnen, anders als ihrem Vater, nicht mehr abverlangt. Namentlich an Moritz war auch in moralischer Hinsicht manches auszusetzen: Er benahm sich wie viele der damaligen Militärs und führte im Verständnis der Zeit ein regelrechtes Lotterleben, indem er, ohne je verheiratet gewesen zu sein, bei sechs unterschiedlichen Frauen insgesamt mindestens acht Kinder zeugte; ${ }^{63}$ obendrein waren seine Trinkgelage sprichwörtlich. Die Dordrechter Synode von 1618/19 entschied er unter Androhung von Gewalt zugunsten der Contraremonstranten, was zur Etablierung der calvinistischen Orthodoxie als privilegierte Kirche in der niederländischen Republik und gleichzeitig zur ersten Abspaltung in den reformierten Reihen führte, durch den erzwungenen Auszug der Remonstranten. Intoleranz in religiosis wurde ihm in dem Zusammenhang von der Nachwelt angelastet. Sein Ruf wurde aber noch nachhaltiger ramponiert durch die von ihm betriebene Hinrichtung, im Gefolge der Synode, des greisen Ratspensionärs Johan van Oldenbarnevelt ${ }^{64}$ (1547-1619), der sich seinerseits hartnäckig weigerte, sich ihm zu beugen und ein Gnadengesuch einzureichen, was aber Moritz längerfristig

\footnotetext{
62 Maljaars (1996) 217-245.

63 Vgl. Iongh (2001) 21-36.

64 NNBw. Bd. 5, Sp. 384-393.
} 
die zweifelhafte Ehre einbrachte, für den ersten Justizmord in den Niederlanden verantwortlich gewesen zu sein. Eine Vorbildrolle konnte ihm somit kaum zugesprochen werden, was sich aber positiv auswirkte auf Friedrich Heinrich, dessen Leben durch die Ehe mit Amalia von Solms in geordneteren Bahnen verlief, der ein geschickterer Stratege und Taktiker war als sein älterer Bruder, in der Familienpolitik internationaler operierte und als Kontrastfigur zu diesem bei seinem Amtsantritt von dem Konvertiten Vondel gar als Hoffnungsträger eines künftigen Klimas der verstärkten religiösen Toleranz begrüßt werden konnte.

Im Mauricius-Lied, das formal und mit zahlreichen intertextuellen Verweisen an das Wilhelmus-Lied anknüpft, ${ }^{65}$ präsentiert Moritz sich, wohl mit impliziter Voraussetzung der Vertrautheit mit dem anderen Gründungsmythos der jungen Republik, dem der Bataver-Nachfolge, ${ }^{66}$ als unerschrockener Bekämpfer der spanischen Gewaltherrschaft, dies allerdings in ausdrücklicher Verbundenheit mit vielen anderen niederländischen Ruhmesgestalten, die namentlich genannt werden, und mit anderen Nassauersprossen, die ihr Leben gaben. Moritz geht es somit als sprechender Ich-Gestalt in erster Linie um Solidarität, was die Strophen 2 und 3 ausdrücklich bestätigen:

Al mijnen lust gepresen/
geweest is vast doorgaens/
Hoe ick doch mocht genesen/
die daer zijn soo goet Spaens.
O lieue Partriotten/
hoe blijf dy dus verblint?
Dat ghy/ die met v spotten/
noch alsoo seer ghesindt.

V mach doch wel ghedencken/

hoe sy tot aller stondt/

Ghesocht hebben te krencken/

65 Das Mauricius-Lied wird im Folgenden zitiert nach dem Einblattdruck in der Leidener Universitätsbibliothek, Sign. Thys. pfl. 1151. Eine deutsche Fassung erschien ebenfalls als Einblattdruck und war als Pendant zu dem des Wilhelmus-Liedes angelegt, vgl. Harms/ Kemp (1987) 122-123. Ein weiteres niederländisches Mauricius-Lied, ebenfalls in der Nachfolge des Wilhelmus-Liedes, erschien 1618 unter dem Titel Liedt Ter eeren van den doorluchtighen Prince van Orangien/Mauritius Grave van Nassau/ etc. o. O. 1618 (Exemplar: Den Haag, Koninklijke Bibliotheek, Sign. Kw pflt 2751); es unterscheidet sich grundlegend von dem vorliegenden und wird hier nicht weiter berücksichtigt.

Dazu besonders auch Schöffer (1975) 78-101. 
dit schoon Landt inden grondt.

All ons trouwe Voor-standers

zijn by haer gantz verdacht

Hoe veel kloecke Neerlanders

zijnder ter doot ghebracht. ${ }^{67}$

[Mein ganzes lobwürdiges Begehren | zielte stets fest darauf, | wie ich diejenigen heilen könnte, | die treu zu den Spaniern halten. | O liebe Landsleute, |warum beharrt ihr in euerer Verblendung? | Daß ihr denjenigen, die euch verspotten, | die Treue haltet. ||

Ihr erinnert euch wohl noch, | wie sie zu allen Zeiten | versucht haben zu zerstören | unser schönes Land bis in den Grund. | All unsere treuen Befürworter | gelten ihnen ohne weiteres als verdächtig. Wie viele tapfere Niederländer | wurden [von ihnen] umgebracht.]

Auch hier findet sich ein Gebet am Schluss. Vielsagend ist aber, dass dabei zuerst, in den Strophen 16 und 17, gleichsam als ein protestantischer Nationalheiliger, Wilhelm von Oranien in seiner Eigenschaft als Vater des Vaterlands und als Garant kollektiver Identität heraufbeschworen wird, bevor dann anschließend Gott selber, in den Strophen 17 und 18, als strafender Richter angefleht wird, zugunsten seines auserwählten Volkes den sprichwörtlichen Stolz der Spanier aus der leyenda negra ${ }^{68}$ vor den Fall kommen zu lassen:

Sow men niet segghen t'waer/

soo ghenoch vuyt eenen Stam/

Om versaedt te zijn? maer/

noch een ander moester an/

Guilelmus van Nassouwen/

sulck Edel Prince wijs

Moest ons oock doen onthouwen/

het moordadich advijs.

O Vader hooch ghepresen

des Vaderlandts soo goet/

Gheensins hebdy v leuen

verschoont tot ons behoet.

67 Mauricius [um 16oo].

68 Zu Funktion der,Schwarzen Legende als stereotype Diffamierung der Weltmacht Spanien vgl. u. a. Hoffmeister (1976) namentlich 33-38. 
Laet nu O God Almachtich/

den Spaenschen hooghen moet/

Eens sincken/ die ghy crachtich/

de grootse vallen doet.

Wilt ons voort-aen behoeden/

voor haer listen so valsch/

En met ons al de goede

voorstanders Duytsch en Walsch.

Wy dancken $v$ met vreuchden/

in dit Nederlandts pleyn:

Want ghy wilt ons in deuchden

beschermen alghemeyn. ${ }^{69}$

[Sollte man nicht sagen, es seien $\mid$ genug gewesen aus ein und demselben Stamm, | um [die Spanier] gesättigt sein zu lassen, aber | noch ein weiterer musste herhalten: | Wilhelm von Nassau, | dieser edle kluge Fürst, | musste uns auch merken lassen | den mörderischen Rat. ||

O hochgelobter Vater | des Vaterlands, der du so getreu bist, | keineswegs hast du dein Leben $\mid$ zu unserem Schutz geschont. | Lass nun, O allmächtiger Gott, | den spanischen Stolz endlich daniederliegen, | der du die Hoffärtigen zu Fall bringst. ||

Behüte uns künftighin | vor deren [der Spanier] trügerischen Ränken | und zugleich mit uns auch die zuverlässigen | Mitstreiter, die deutschen [niederländischen?] wie die französischen. |Wir danken dir voller Freude | in den gesamten Niederlanden, | denn du wirst uns, sofern wir tugendhaft bleiben, insgemein beschützen.]

Das ist alles sehr viel flacher und weniger kunstvoll als im Wilhelmus-Lied. Es wird aber das niederländische Selbstbild um die Komponente der Freiheitlichkeit in bester Bataver-Tradition angereichert.

Vondel strickt in seinem Princelied auf Friedrich Heinrich, indem auch er das Wilhelmus-Lied formal aufgreift und intertextuell verwertet, am bewährten Identitätsmuster weiter, wobei er die Komponente der interkonfessionellen Toleranz hinzufügt. Der sprechend eingeführte Friedrich Heinrich setzt zur Verwirklichung nationaler Solidarität und Einheitlichkeit auf tätige Liebe als Ergebnis der Gewissenfreiheit:

69 Mauricius [um 16oo]. 
's Lands rechten en vryheden
Ick helpen sal in zwang;
In geen' vereende steden
Gewetens felle dwang
Of tyrannye lyen:
Ick wensch de goe gemeent
En trouwe borgeryen
Door liefd' te sien vereent. ${ }^{70}$

[Des Landes Rechten und Privilegien | werde ich zur Geltung verhelfen; | in keiner der vereinigten Städte | scharfen Gewissenszwang | oder Tyrannei erdulden: | Mein Wunsch ist es, das Gemeinwesen | und die getreue Bürgerschaft | in Liebe vereint zu sehen.]

Anders als in der Vorlage endet Vondels Lied nicht mit einem Gebet, sondern mit Vorschusslorbeeren, die Friedrich Heinrich als Kämpfer auf Gottes Seite für sich in Anspruch nimmt:

Soo ick met zege keere

En Spanje dwing tot vre, Singt Gode prijs en eere

Die voor ons' vesten stre. Ick sie alree nae 't vechten De maeghden mijn' banier Ontmoeten, die my vlechten Den lofkrans van laurier. ${ }^{71}$

[Falls ich als Sieger heimkehre | und Spanien den Frieden abnötige, | sollt ihr Gott lobsingen und ehren, | der für unsere Festungen kämpfte. | Ich sehe bereits nach dem Kampf | die Jungfrauen meinem Banner | entgegentreten, die mir flechten | zu Lobe den Lorbeerkranz.]

Das zeigt nicht nur, dass Friedrich Heinrich noch Hoffnungsträger war, dass die Bewährung, die sein Märtyrervater Wilhelm längst abgeleistet hatte, in seinem Fall noch ausstand, weiter dass das Vertrauen, das in den jungen Prinzen gesetzt wurde, sich zunächst einmal aus der Abgrenzung gegen den älteren,

$70 \quad$ Vondel (1928) 505 .

71 Vondel (1928) 506. 
weniger toleranten, Bruder und Amtsvorgänger ergab, es zeigt aber vor allem, dass die niederländische Identität, die 1625 , als Vondels Lied veröffentlicht wurde, mittlerweile drei Oranier-Prinzen nacheinander in politischen Liedern als sprechende Ich-Gestalten, und das heißt somit, in größter Unmittelbarkeit der Aussage, heraufbeschworen hatten, nach wie vor eine Baustelle war, ein im Entstehen begriffenes Konstrukt. Das aber gehört schlechthin zur Eigenheit von Identitäten aller Art: Sie sind ein ständiges Werden.

\section{8} Schluss

Ein sprechendes Ich scheint in der Versdichtung der Frühen Neuzeit besonders dort bevorzugt worden zu sein, wo Religion, oder besser noch Konfessionalität, und Politik aufeinanderstoßen und wo es somit in mehrfachem Sinne um die Konstruktion von Identität, auf der Grundlage eines neuen nationalen oder konfessionellen Selbstverständnisses, geht. Eine solche Identität kann in der Abgrenzung zum Negativen hin oder im Zuge der Identifikation durch die Stiftung von Gemeinsinn als Positivpotenz realisiert werden. Ersteres wurde an der dichterischen Auseinandersetzung mit Heinrich dem Jüngeren von Braunschweig aufgezeigt, letzteres am Wilhelmus-Lied und der Tradition, die es evozierte. Je nach der Zielrichtung, Abgrenzung oder Identifikation, lässt sich eine Zweisträngigkeit von Prozessen aus Einzelphänomenen, die zum Einsatz kommen, beobachten. Die Abgrenzung realisiert sich eher als Klage, die sprechende Person wird hier als Antiheld der Lächerlichkeit preisgegeben, bevorzugt in einen teuflisch-dämonischen oder heidnisch-mythologischen Funktionszusammenhang eingebunden oder mit großen Verbrechern aus der profanen sowie der sakralen Geschichte in Verbindung gebracht; er macht seine Rechnung ohne Gott, lässt sich Hybris zuschulden kommen, und seine hochfliegenden Pläne scheitern am Ende. Die positive Identifikationsgestalt spricht dagegen eher eine Mahnrede oder verteidigt in apologetischem Sinne die gute Sache, erscheint als wahrhafter Held, der Gottes Hilfe auf Schritt und Tritt erfährt, ist standhaft auch im Unglück, und zeichnet sich aus durch Mut, wo sein negativ besetztes Gegenstück eher feige ist. Im ersteren Fall wird die Klage zumeist mittelbar mitgeteilt, über einen Erzähler beziehungsweise Beobachter, was Distanz schafft, dafür ist die Belehrung eher explizit und der Ton polemisch beziehungsweise ironisch; im letzteren, wo vielmehr auf Identifikation gesetzt wird, spricht der Held unmittelbar, was Nähe bewirkt, fehlt die Didaxis oder ist sie implizit, und wird stärker an die emotio appelliert. Hier finden sich inbrünstige Gebete, dort pervertierte Sakralität. Am Ende scheint die Zweisträngigkeit der Darstellung des sprechenden Ichs in der politischen Versdichtung mit 
dem augustinischen Zweistaatenmodell zu korrespondieren, das in der Frühen Neuzeit wieder verstärkt Aufmerksamkeit erfuhr. ${ }^{72}$ So dürfte der Sinn frühneuzeitlicher Versdichtung, insofern sie den sprechenden Helden bemühte, nicht zuletzt auch darin liegen, dass sie die Aporie von Gut und Böse, die in den Unbilden der Zeit umfassend erfahren wurde, in der Konstruktion kollektiver Identitäten zu entschärfen versucht.

\section{Literaturverzeichnis}

\section{Primärliteratur}

Bekentnis und Clag Herzog Heinrichs von Braunschweig des Iüngern. ${ }^{2} 1863$. In Satiren und Pasquille aus der Reformationszeit. Bd. 1, hgg. von O. Schade. Hannover: 68-76.

Bekentnus vnd clag hertzog Heinrichen von Braunschweigs des Jüngern aller seiner hendel/ vnd wie er seine sachen hinfort anzustellen gedencket. o. O. o.J. Exemplar: Wolfenbüttel, Herzog August Bibliothek, Sign. Gn Sammelbd. 10 (6). Vgl. auch https:// download.digitale-sammlungen.de/pdf/1377597214bsb10202854.pdf. [abgerufen: 27.8.2013].

Liedt Ter eeren van den doorluchtighen Prince van Orangien/Mauritius Grave van Nassau/ etc. o. O. 1618. Exemplar: Den Haag, Koninklijke Bibliotheek, Sign. KW pflt 2751. Vgl. auch https://books.google.nl/books?id=wvlGAAAAcAAJ\&pg=PP3\#v=onepage \&q\&f=false [abgerufen: 20.12 .2010$]$.

Das Ambraser Liederbuch vom Jahre 1582, hgg. von J. Bergmann. Stuttgart 1845 (Bibliothek des Literarischen Vereins in Stuttgart 12).

Liliencron R. von. 1869. Die historischen Volkslieder der Deutschen vom 13. bis 16. Jahrhundert. Bd. 4. Leipzig.

Liliencron R. von. 1884. Deutsches Leben im Volkslied um 1530. Berlin /Stuttgart (Kürschners Deutsche National-Litteratur 13).

Luther, M. 1914. Wider Hans Worst 1541. In Ders. Werke. Kritische Gesamtausgabe. Bd. 51. Weimar: $461-572$.

Mauricius van Nassouwen ben ick van Duytschen bloet. o. O. o.J. [um 16oo]. Exemplar: Leiden, Universitätsbibliothek, Sign. Thys. pfl. 1151. Vgl. auch http://www.liederen bank.nl/text.php?recordid=22782\&lan=nl [abgerufen: 1.7.2009].

Vondel, J. van den. 1928. Princelied. In Ders. De werken. Volledige en geïllustreerde tekstuitgave in tien deelen. Bd. 2. Amsterdam, 505-506.

Waldis, B. 1883. Streitgedichte gegen Herzog Heinrich denJüngernvon Braunschweig, hgg. von F. Koldewey. Halle (Neudrucke deutscher Litteraturwerke des XVI. und XVII. Jahrhunderts 49).

Vgl. zu dessen Nachwirkung bis in die Literatur der Frühen Neuzeit Pecher (2007). 


\section{Forschungsliteratur}

ADB = Liliencron, R. von, Wegele, F.X. von (Hg.) 1875-1912. Allgemeine Deutsche Biographie. Leipzig. 56 Bde.

Baumgartner, A. 1882. Joost van den Vondel, sein Leben und seine Werke. Ein Bild aus der Niederländischen Literaturgeschichte. Freiburg i. Br.

Bruin, M. de. 1998. Het Wilhelmus tijdens de Republiek. In: Nationale hymnen. Het Wilhelmus en zijn buren, hgg. von Louis Peter Grijp. Nijmegen / Amsterdam: 16-42.

Brunner, H. 1975. Die alten Meister. Studien zur Überlieferung der mittelhochdeutschen Sangspruchdichter im Spätmittelalter und in der Frühen Neuzeit. München (Münchener Texte und Untersuchungen zur deutschen Literatur des Mittelalters 54).

Buchenau, G. 1858. Burcard Waldis. In: [Jahresprogramm des Kurfürstlichen Gymnasiums zu Marburg] Zu der öffentlichen Prüfung des Kurfürstlichen Gymnasiums zu Marburg im Jahre 1858. Marburg, 1-40.

Coigneau, D. 1984. Rederijkersliteratuur. In: Historische Letterkunde. Facetten van vakbeoefening, hgg. von M. Spies. Groningen: 35-57.

Deursen, A.Th. van. 1995. Willem van Oranje. Een biografisch portret. Amsterdam.

Deursen, A.Th. van. 2000. Maurits van Nassau 1567-1625. De winnaar die faalde. Amsterdam.

Duyse, F. van. 1905. Het oude Nederlandsche lied. Wereldlijke en geestelijke liederen uit vroegeren tijd. Teksten en melodieën. Bd. 2. 's-Gravenhage / Antwerpen.

Frank, H.J. 1993. Handbuch der deutschen Strophenformen. Tübingen/ Basel (UniTaschenbücher 1732).

Goedeke, K. 1852. Burchard Waldis. Hannover.

Grijp, L.P. 1998. Nationale hymnen in het Koninkrijk der Nederlanden, I: 1813-1939, In: Nationale hymnen. Het Wilhelmus en zijn buren, hgg. von dems. Nijmegen / Amsterdam, 44-73.

Harms, W., Kemp, C. (Hg.) 1987. Die Sammlungen der Hessischen Landes- und Hochschulbibliothek. Darmstadt (Deutsche illustrierte Flugblätter des 16. und 17. Jahrhunderts 4$)$.

Hoffmeister, G. 1976. Spanien und Deutschland. Geschichte und Dokumentation der literarischen Beziehungen. Berlin (Grundlagen der Romanistik 9).

Iongh, H. de. 2001. Oranjebastaarden. Een vademecum. Soesterberg.

Kloek, J., Mijnhardt, W. 2001. 1800. Blauwdrukken voor een samenleving. Den Haag (Nederlandse cultuur in Europese context 2).

Koldewey, F. 1883. Heinz von Wolfenbüttel. Ein Zeitbild aus dem Jahrhundert der Reformation. Halle (Schriften des Vereins für Reformationsgeschichte I/2).

Könneker, B. 1975. Die deutsche Literatur der Reformationszeit. München.

Lademacher, H. 2007. Phönix aus der Asche? Politik und Kultur der niederländischen Republik im Europa des 17. Jahrhunderts. Münster u.a. (Studien zur Geschichte und Kultur Nordwesteuropas 16). 
Maljaars, A. 1996. Het Wilhelmus. Auteurschap, datering en strekking. Een kritische toetsing en nieuwe interpretatie. Kampen.

Meeuwesse, K. 1951. Het Wilhelmus. Structuur en strekking. In: De Gids 114: 393-405.

Meeuwesse, K. 1964. Wilhelmus van Nassouwe Rhetor. In: Handelingen van het achtentwintigste Nederlands Filologencongres, gehouden te Nijmegen op woensdag 1, donderdag 2 en vrijdag 3 april 1964. Groningen, 8-29.

Mittler, F.L. 1855. Herzog Heinrichs von Braunschweig Klagelied. Mit einem Nachworte über das Leben und die Dichtungen des Burkard Waldis. Vermehrter Abdruck aus dem Hessischen Jahrbuche für 1855. Kassel.

Mörke, O. 2007. Wilhelmvon Oranien (1533-1584). Fürst und,Vater'der Republik. Stuttgart (Urban-Taschenbücher 6o9).

Müller, U. 1974. Untersuchungen zur politischen Lyrik des deutschen Mittelalters. Göppingen (Göppinger Arbeiten zur Germanistik 55-56).

NDB $=$ Historische Kommission bei der Bayerischen Akademie der Wissenschaften (Hg.) 1953-. Neue Deutsche Biographie. Berlin. Bisher 26 Bde.

Nehlsen, E. 1993. Wilhelmus van Nassauen. Studien zur Rezeption eines niederländischen Liedes im deutschsprachigen Raum vom 16. bis ins 20. Jahrhundert. Münster / Hamburg (Niederlande-Studien 4).

NNBW = Molhuysen, Ph.C., Blok, P.J., Knappert, L., Kossmann, F.K.H. (Hg.) 1911-1937. Nieuw Nederlandsch Biografisch Woordenboek. Leiden. 10 Bde.

Pecher, C.M. 2007. Das Weltkonzil von Trient in franziskanischer Vermittlung. Eine Studie über das Werk,De civitate et civibus Dei ac de civitate civibusque Satanae' des Südtiroler Franziskanergelehrten Ludovicus Boroius (o.F.M.). München (Kulturgeschichtliche Forschungen 29).

Pleij, H. 2007. Het gevleugelde woord. Geschiedenis van de Nederlandse literatuur 14001560. Amsterdam (Geschiedenis van de Nederlandse literatuur 3).

Poelhekke, J.J. 1978. Frederik Hendrik, Prins van Oranje. Een biografisch drieluik. Zutphen.

Porteman, K., Smits-Veldt, M.B. 20o9. Een nieuwvaderland voor de muzen. Geschiedenis van de Nederlandse literatuur 1560-1700. Amsterdam (Geschiedenis van de Nederlandse literatuur 4).

Schöffer, I. 1975. The Batavian Myth during the Sixteenth and Seventeenth Centuries. In: Some Political Mythologies. Papers delivered to the Fifth Anglo-Dutch Historical Conference, hgg. von J.S. Bromley und E.H. Kossmann. Den Haag, 78-101.

Stopp, F.J. 1970. Henry the Younger of Brunswick-Wolfenbüttel. Wild Man and Werwolf in Religious Polemics 1538-1544. In: Journal of the Warburg and Courtauld Institutes 33: $200-234$.

Zandvliet, K. (Hg.) 200o. Maurits, Prins van Oranje. Amsterdam, Zwolle. 